\title{
Bor ve Flor Katkılanmış ZnO İnce Filmlerinde K Tabakası Flüoresans Verimlerinin XRF Tekniği ile Ölçülmesi
}

\section{Measurement of K Shell Fluorescence Yields in Boron and Fluorine-dloped ZnO Thin Films by XRF Technique}

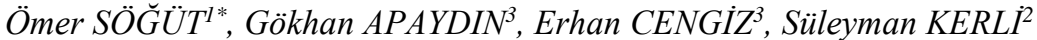

\begin{abstract}
${ }^{1}$ Kahramanmaraş Sütçü İmam Üniversitesi, Fen Edebiyat Fakültesi, Fizik Bölümü, Kahramanmaraş, Türkiye
${ }^{2}$ Kahramanmaraş Sütçü İmam Üniversitesi, Elbistan Teknoloji Fakültesi, Enerji Sistemleri Mühendisliği, Kahramanmaraş, Türkiye ${ }^{3}$ Karadeniz Teknik Üniversitesi, Fen Fakültesi, Fizik Bölümü, Trabzon, Türkiye
\end{abstract}

*Sorumlu Yazar / Corresponding Author: Ömer SÖĞÜT, osogut@ksu.edu.tr

\section{ÖZET}

Bu çalışmada, kimyasal püskürtme yöntemi ile \%1-5 oranında flor katkılanılarak ve \%2-5 oranında bor katkılanılarak üretilen, $\mathrm{ZnO}$ (çinko oksit) ince filmlerde çinkonun K tabakası flüoresans verimlerinin $\left(\omega_{K}\right)$ bor ve flor katkı miktarlarına göre değişimi, $X$-ışını Flüoresans (XRF) tekniği ile incelendi. Numuneleri uyarmak için $50 \mathrm{mCi}$ şiddetinde ve $59.543 \mathrm{keV}$ enerjili fotonlar yayınlayan bir ${ }^{24 l} \mathrm{Am}$ radyoizotop kaynağı kullanıldı. Numunelerden yayınlanan karakteristik $K X$-ıșınlarını saymak için 5.96 keV'de yarı maksimumdaki tam genişliği (FWHM) 150 $\mathrm{eV}$, aktif alanı $30 \mathrm{~mm}^{2}$ ve kalınlığ $5 \mathrm{~mm}$, polimer pencere kalınlı̆̆ $0.4 \mu \mathrm{m}$ olan Ultra-LEGe dedektörü kullanıldl. Flor katkllanarak üretilen $\mathrm{ZnO}$ ince filmlerinde florun katkı miktarl artarken K kabuğu flüoresans verim değerleri azalmıștır. Ancak, bor ekleyerek üretilen $\mathrm{ZnO}$ ince filmlerde, bor katkusı artarken $K$ kabuğu flüoresans verim değerleri de artmıştır. Bunun nedeni $\mathrm{ZnO}$ ince filmine bor ve flor ilavesinin $\mathrm{ZnO}$ yapisinda perdeleme etkisi, bağ uzunluğu, kafes simetrisi gibi bazı etkileşimleri değiştirmesi olabilir. $B u$ değişimde $K X$-ısıını yayınlama ihtimalini değiștirir. $K$ tabakasl flüoresans verimlerinin flor ve bor katkı miktarlarına göre değişimlerinin nedenlerinden biri de, katkllanan flor ve borun $\mathrm{ZnO}$ ince filmindeki oksijen iyonlar ile yer değiştirmesi olabilir. Bunlara ek olarak, elementler kimyasal bileşiklerde yer alırlarsa, yayınladıkları X-ışııı çizgisinin dalga boyunda, çizgi şiddetinde ve şeklinde değişimler görülür.

Anahtar Kelimeler: ZnO, Flor, Bor, İnce Film, Flüoresans Verim, K Kabuğu, Kimyasal Etki.

\section{ABSTRACT}

\begin{abstract}
In this study, the variation of $K$ shell fluorescence yields $\left(\omega_{K}\right)$ of zinc according to the amounts of boron and fluorine additives in $\mathrm{ZnO}$ (zinc oxide) thin films that produced by 1-5\% fluorine and 2-5\% boron doping by chemical spray method were investigated by $X$-ray Fluorescence (XRF) technique. $A{ }^{241} \mathrm{Am}$ radioisotope source emitting $59.543 \mathrm{keV}$ energy gamma rays at $50 \mathrm{mCi}$ intensity was used to excite the produced thin film samples. An Ultra-LEGe detector (FWHM $150 \mathrm{eV}$ at $5.9 \mathrm{keV}$, active area $30 \mathrm{~mm}^{2}$, thickness $5 \mathrm{~mm}$, polymer window thickness $0.4 \mu \mathrm{m})$ were used to count the characteristic $K X$-rays emitted from the samples. In the $\mathrm{ZnO}$ thin films produced by adding fluorine, while the amount of fluorine additive increased the $K$ shell fluorescence yield decreased. However, in the $\mathrm{ZnO}$ thin films produced by adding boron, while the amount of boron additive increased the $K$ shell fluorescence yield values also increased. This may be due to the fact that the boron and fluorine addition to the $\mathrm{ZnO}$ thin film change some interactions such as the screening effect, bond length, the lattice symmetry in $\mathrm{ZnO}$ structure. In this change, $K$ changes the probability of $X$-ray emission. One of the reasons for the variation of the $K$ shell fluorescence yields with respect to fluorine and boron additive amounts may be the displacement of added fluorine and boron with the O-ions in the $\mathrm{ZnO}$ thin film. In addition, if the elements are taken apart in chemical compounds, they will show variations in the wavelength, line intensity and shape of the $X$ ray line that are emitted.
\end{abstract}

Keywords: ZnO, Fluorine, Boron, Thin Film, Fluorescence Yield, K Shell, Chemical Effect.

\section{GİRIŞ̧}

2000 yıldan daha fazla bir zaman önce, kuyumcular ve gümüşçüler, bir yapıştırıcı olarak cıvanın kullanımı dâhil olmak üzere ince metal filmleri heykellere ve diğer nesnelere uygulamak için çeşitli yöntemler geliştirdiler. İyi donanımlı yeni ince film teknikleri, kolay kullanım, kesinlik, seçicilik, hız, doğruluk ve hassasiyet ile geniş erişilebilirliğe sahiptir (Zhang, 2010; Bakoglidis ve ark., 2015; Gallop ve Hao, 2016). İnce filmler, nanometre kesrinden birkaç mikrometre kalınlığa kadar değişen ince malzeme tabakalarıdır. İnce film teknolojisi ve bu teknolojiyle üretilen filmlerin özelliklerinin incelenmesi hem yakın geçmişte hem de günümüzde büyük önem taşımaktadır. Bir malzemenin yüzeyi ince fillmle kaplanırsa, malzemeye daha önce 
sahip olmadığı bazı özellikler verebilir. Bu nedenle, bu filmler, optik, elektronik, manyetik, kimya ve mekanik gibi endüstriyel alanlarda yüksek teknolojili malzemeler olarak kullanılmaktadır (Söğüt ve ark., 2014).

$\mathrm{ZnO}$, doğrudan bant aralığı olan, II-VI grubu yarı iletkenidir $\left(\mathrm{E}_{\mathrm{g}}=3,37 \mathrm{eV}\right)$. ZnO'nun elektronik iletkenliği, aradaki iyonize çinko atomlarına ve kristal yapının içindeki boşluklara bağlı olarak üretilen elektronlara atfedilir. Belirli bir konsantrasyon seviyesine kadar uygun bir katkı maddesi, ZnO'daki iletkenlik bandına elektron verici olarak hareket edebilir ve böylece elektrik iletkenliğini arttırır. Katkı maddesinin yapısına bağlı olarak, ZnO bir n veya p tipi yarı iletken olabilir (Salam ve ark., 2013). $\mathrm{ZnO}$ ince filmleri saydam, iletken oksit grubunda oldukları için görünür bölgede yüksek optiksel geçirgenliğe ve yüksek elektriksel iletkenliğe sahiptirler. Genellikle hekzagonal wurtzite kristal yapısına sahip olan ZnO'nun bant aralığı 3.1-3.4 eV arasında değişmektedir. ZnO gibi saydam iletken oksit yariiletken filmler uygun optik ve elektriksel özellikleri nedeniyle son yıllarda yoğun bir şekilde araştırma konusu olarak ilgi çekmiştir. $\mathrm{ZnO}$ hem mikroelektronik hem de optoelektronik cihazlarda çeşitli uygulamalar için kullanılan ve üzerinde birçok araştırma yapılan çok kullanışlı malzemelerdir. ZnO filmler; güneş pillerinde, gaz sensörlerinde, UV dedektörlerinde, düz panel göstergelerde, optoelektronik devre aygitlarında, piezoelektrik güç çeviricilerde, termoelektrik aygıtlarda, $\mathrm{pH}$ sensörlerinde, biosensörlerde, ince film transistörlerde, fotoelektrik cihazlarda, yüzey ses dalga devrelerinde ve ultra-yüksek frekans elektro-ses dönüştürücülerinde kullanılmaktadır (Fahrenbruch, 1997; Natsume ve ark., 2000; Tsay ve ark., 2010). Son yıllarda, ZnO'ya yönelik araştırmalar Al, Ga ve diğer üç ana grup metal elementine genişlemesine odaklanmıştır (Wong ve ark., 2011; Nian ve ark., 2014; Gho ve ark., 2011; Naik ve ark., 2013; Dhara ve ark., 2012), ancak metal elementler, taşıyıcı konsantrasyonu ve stabilitesinin geliştirilmesinde çok güçlü bir avantaja sahiptir ve bu metal katkılı ZnO ince filmlerin temel özelliği olan optik şeffaflık, büyük ölçüde yüksek taşıyıcı konsantrasyonu ve düşük hareketliliği ile sınırlanmıştır (Li ve ark., 2017; Chen ve ark., 2013; Zou ve ark., 2012; Wang ve ark., 2010; Ip ve ark., 2003).

Çeşitli elementler için X-ş̧ıı üretim tesir-kesitlerinin ve flüoresans verimlerinin hesaplanması kimyasal fizik, atomik ve moleküler fizik çalışmalarında, XRF elemental analizlerinde, ışınlama işlemlerinde, tıbbi araştırmalar ve nükleer fizik gibi birçok alandaki uygulamaları nedeniyle çok önemlidir. XRF yönteminde numune hazırlama sürecinin hızlı ve analizlerde numuneler tahribat edilmediği için, malzemelerin kontrolü, saha uygulamaları ve endüstriyel üretim için tercih edilen bir yöntemdir. XRF ölçümlerinin tekrarlanabilirliliği ve hassaslı̆̆ çok yüksektir (Baydaş ve ark., 2009; Tiraşoğlu ve Söğüt, 2008; Şimşek ve ark., 2002; Kahoul ve ark., 2011).

$\mathrm{Bu}$ çalışmanın amacı, çeşitli konsantrasyonlarda bor (\%2-4) ve flor (1-5) katkılanarak üretilmiş olan ZnO ince filmlerindeki çinkonun K tabakası flüoresans verimlerinin $\left(\omega_{\mathrm{K}}\right)$ bor ve flor katkı miktarlarına göre değişimini incelemektir.

\section{MATERYAL VE METOD}

Kimyasal püskürtme yöntemi ile \%1-5 oranında flor katkılanılarak (ZnO:F) ve \%2-5 oranında bor katkılanılarak üretilen ( $\mathrm{ZnO}: \mathrm{B})$ ince filmlerde çinkonun $\mathrm{K}$ tabakası flüoresans verimlerinin $\left(\omega_{\mathrm{K}}\right)$ bor ve flor katkı miktarlarına göre değişimi $\mathrm{X}$-ışını flüoresans (XRF) tekniği ile incelendi. Numuneleri uyarmak için $50 \mathrm{mCi}$ şiddetinde ve $59.543 \mathrm{keV}$ enerjili fotonlar yayınlayan bir ${ }^{241} \mathrm{Am}$ radyoizotop kaynağı kullanıldı. Numunelerden yayınlanan karakteristik K X-1şınlarını saymak için $5.96 \mathrm{keV}$ 'de yarı maksimumdaki tam genişliği (FWHM) $150 \mathrm{eV}$, aktif alanı $30 \mathrm{~mm}^{2}$ ve kalınlığ $5 \mathrm{~mm}$, polimer pencere kalınlı̆̆ $0,4 \mu \mathrm{m}$ olan UltraLEGe dedektörü kullanıldı. Sayma istatistiğinden gelebilecek hataları en aza indirmek için numuneler en az 5000s gerçek sayma zamanı (live time) ile sayıldı. Şekil 1'de deney geometrisi verilmiştir. Şekil 2'de EDXRF sisteminde alınmış \%3 flor katkılanmış $\mathrm{ZnO}$ ince filminin $\mathrm{K} \mathrm{X}$-1şını spektrumu verilmiştir.

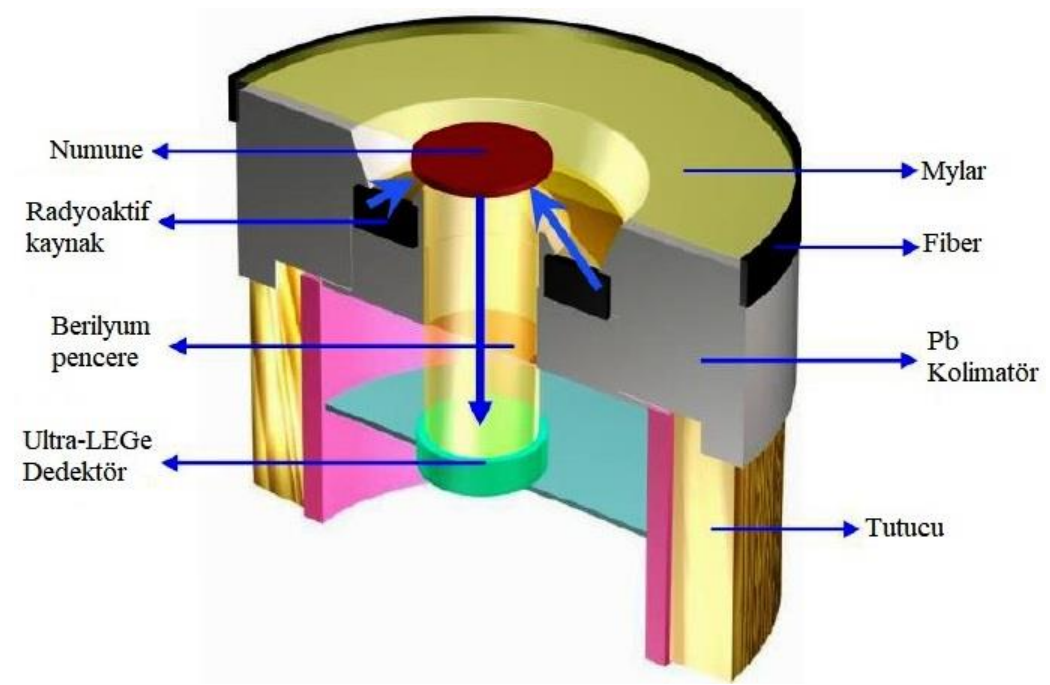

Şekil 1. Deney Geometrisi 


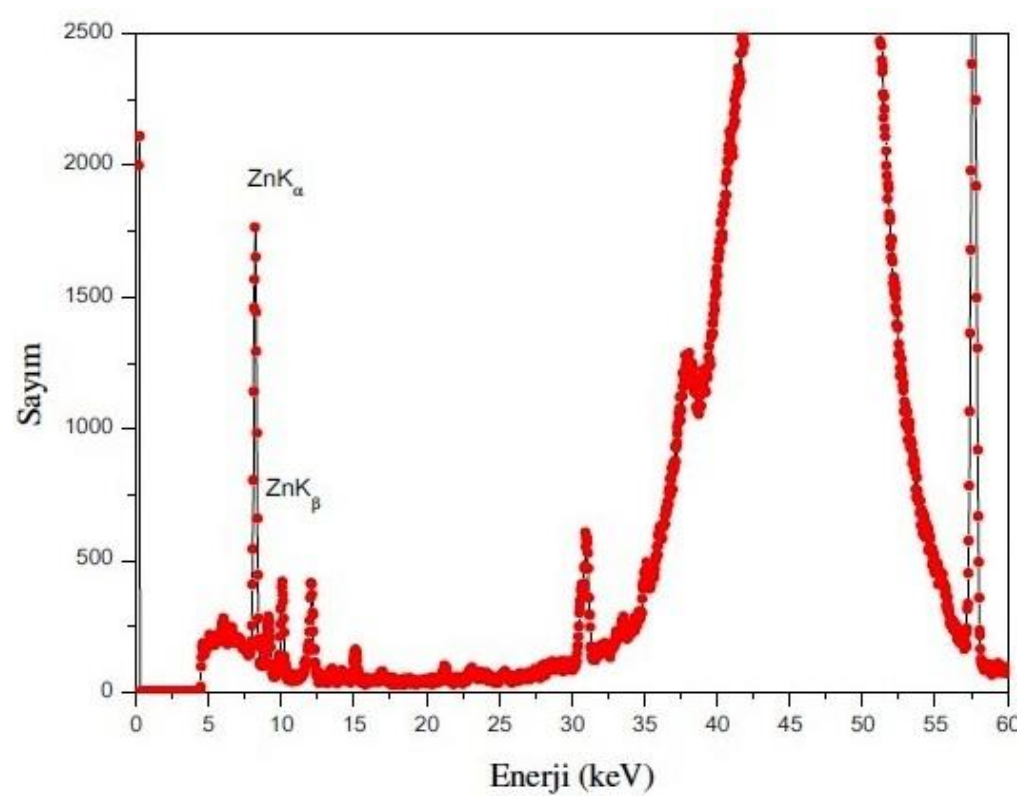

Şekil 2. \%3 Flor Katkılanmış ZnO İnce Film Spektrumu

$\mathrm{K}$ tabakası flüoresans verimi hesaplamak için aşă̆ıdaki denklemler kullanıldı.

$$
\omega_{\mathrm{K}}=2-\eta_{\mathrm{KL}}\left\{1+\left(\frac{\mathrm{IK} \beta}{\mathrm{IK} \alpha}\right)\right\}
$$

Burada $\eta_{\mathrm{KL}} \mathrm{K}$ tabakasından $\mathrm{L}$ tabakasına boşluk geçiş ihtimalini temsil etmektedir ve teorik olarak hesaplandı. $\omega_{\mathrm{K}}, \mathrm{K}$ tabakası flüoresans verimi göstermektedir ve yarı deneysel olarak ölçülen IK $\beta / \mathrm{IK} \alpha \mathrm{KX}$-şsılları şiddet oranlarının değerleri kullanılarak hesaplandı. IK $\beta / \mathrm{IK} \alpha \mathrm{K}$ X-1şılları şiddet oranları deneysel olarak hesaplamak için aşağıdaki denklem kullanıldı.

$$
\frac{\mathrm{IK} \beta}{\mathrm{IK} \alpha}=\frac{\mathrm{NK} \beta}{\mathrm{NK} \alpha} \frac{\mathrm{I}_{0} \mathrm{G} \varepsilon_{\mathrm{K} \alpha}}{\mathrm{I}_{0} \mathrm{G} \varepsilon_{\mathrm{K} \beta}} \frac{\beta_{\mathrm{K} \alpha}}{\beta_{\mathrm{K} \beta}}
$$

Burada NK $\alpha$ ve NK $\beta$, sırasıyla K $\alpha$ ve $K \beta$ piklerinin altlarındaki net alanlardır. $\mathrm{I}_{0}$ kaynağın şiddetini, $G$ geometri faktörünü, $\varepsilon$ dedektör verimini ve $\beta_{K \alpha}$ ve $\beta_{K \beta}$ sırasıyla soğurma düzeltme faktörlerini göstermektedir. Dedektör verimi her enerji için farklı değerler aldığı için çalışılan enerji aralığında dedektör verim eğrisinin belirlenmesi gereklidir. Bir dedektörün belirli bir enerjideki verimi, dedektörden sabit uzaklıkta bulunan standart kaynaktan birim zamanda dedektöre gelen fotonların sayısının belirlenmesi ile tespit edilir. Detektör verimliliğini ölçmek için analit tarafından yayınlanan karakteristik K $\alpha$ ve K $\beta$ X-1şınları kullanılır. Ancak genellikle açısal dağlıma bağlı olmadığı için Ka X-ışınları tercih edilir. Elementler radyoizotop bir kaynakla uyarılır ve analitten yayınlanan karakteristik X-ışınları detektörde sayılır, oluşan $K \alpha$ ve $K \beta$ piklerinin net alanları alınır ve aşağıdaki denklem yardımı ile detektör verimliliği hesaplandı.

$$
\mathrm{I}_{0} \mathrm{G} \varepsilon_{\mathrm{i}}=\frac{\mathrm{N}_{\mathrm{i}}}{\sigma_{\mathrm{Ki}} \beta_{\mathrm{i}} \mathrm{t}}(\mathrm{i}=\alpha, \beta)
$$

Burada $\sigma_{\mathrm{Ki}}(\mathrm{i}=\alpha, \beta)$ standart elementin $\mathrm{K} \alpha$ veya $\mathrm{K} \beta$ flüoresans tesir kesiti, $\beta \mathrm{i}$ uyarıcı fotonun ve numunenin $\mathrm{K} \alpha$ ve $\mathrm{K} \beta$ enerjisine göre özsoğurma düzeltmesi, t ise numunenin kalınlı̆̆ıdır. Şekil 3'de dedektör verim eğrisinin grafiği verilmiştir. 


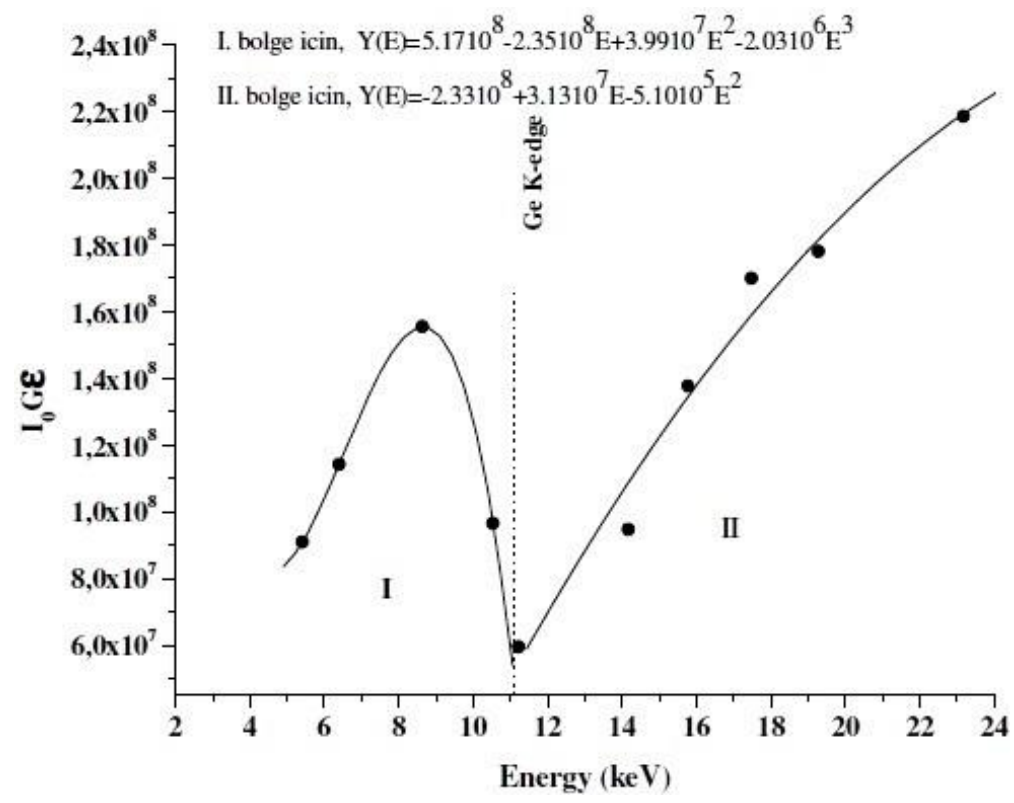

Şekil 3. $\mathrm{I}_{0} \mathrm{G} \varepsilon$ Dedektör Verim Eğrisinin Grafiği

$\beta_{\mathrm{i}}$ özsoğurma düzeltme faktörü aşağıdaki denklem yardımı ile hesaplandı.

$$
\beta_{\mathrm{i}}=\frac{1-\exp \left\{(-1)\left(\mu_{\mathrm{p}} \sec \theta+\mu_{\mathrm{e}} \sec \varphi\right) \mathrm{t}\right\}}{\left(\mu_{\mathrm{p}} \sec \theta+\mu_{\mathrm{e}} \sec \varphi\right) \mathrm{t}}
$$

Burada $\theta$ ve $\varphi$, sırasıyla, kaynaktan gelen radyasyon ve yayımlanan karakteristik X-1şıllarının, numune yüzeyi ile yaptıkları açılardır. $\mu_{\mathrm{p}}\left(\mathrm{cm}^{2} / \mathrm{g}\right)$ ve $\mu \mathrm{e}\left(\mathrm{cm}^{2} / \mathrm{g}\right)$, sırasıyla kaynaktan gelen radyasyon ve yayınlanan karakteristik X-1şınları için numunenin toplam kütle soğurma katsayılarıdır (Hubbell ve Seltzer, 1995). t (g/cm²) numunenin kalınlığıdır.

\section{BULGULAR VE TARTIŞMA}

Çeşitli konsantrasyonlarda püskürtme yöntemi ile üretilen flor ve bor katkılı $\mathrm{ZnO}$ ince film numunelerinde çinkonun $\mathrm{K}$ tabakası flüoresans verimlerinin $\left(\omega_{\mathrm{K}}\right)$ flor ve bor katkı miktarlarına göre değişimi XRF tekniği ile araştırıldı. K tabakası flüoresans verimlerin deneysel ve teorik sonuçları Tablo 1'de verildi. Tablo 1'den görüldüğü gibi flüoresans verim değerleri flor ve bor katkı miktarlarına göre karşılaştırıldı. Hesaplamalardaki muhtemel hatalar, $\omega_{\mathrm{K}}$ değerlerini hesaplamak için kullanılan farklı parametrelerdeki belirsizliklerden kaynaklanmaktadır. Bu hata kaynakları, $\mathrm{K} \alpha$ ve $\mathrm{K} \beta \mathrm{X}$-ışını piklerin altındaki alanın değerlendirmesi (\% 3), öz-soğurma düzeltme faktörünün hesaplanması (\% 4), dedektör veriminin tespiti (\% 2), numune kalınlığının belirlenmesi (\% 1) nedeniyle yapılan ölçümlerdeki belirsizliklerdir ve toplam hata \%6-10'dur. Elde edilen sonuçlar diğer deneysel ve teorik değerler ile karşılaştırıldı. Sonuçlar deneysel hatalar içinde diğer araştırmacılarının sonuçları ile uyum içindedir. Tablo 1'den görüldüğü gibi, katkısız ZnO ince filmin $\omega_{\mathrm{K}}$ değerleri \%1-5 flor ve $\% 2-5$ bor katkılı $\mathrm{ZnO}$ ince filmin $\omega_{\mathrm{K}}$ değerlerinden \%1-4 farklıdır. Bu farklılık Krause'ya göre \%4 (Krause, 1979), Hubbell ve arkadaşlarına göre \%3 (Hubbell, ve ark., 1994), Fink ve arkadaşlarına göre \%12 (Fink ve ark., 1966), Garg ve arkadaşlarına göre \%3 (Garg ve ark., 1985), Bambynek ve arkadaşlarına göre \%3 (Bambynek ve ark., 1972) ve Broll'e göre \%1 (Broll, 1986) dir. Bununla birlikte, 1-5 flor ve \%2-5 bor katkılı ZnO ince filmin $\omega_{\mathrm{K}}$ değerlerinde Krause'ya göre \%3-7 ve \%4-8 (Krause, 1979), Hubbell ve arkadaşlarına göre \%1-5 ve \%2-7 (Hubbell, ve ark., 1994), Fink ve arkadaşlarına göre \%11-15 ve \%12-17 (Fink ve ark., 1966), Garg ve arkadaşlarına göre \%1-5 ve 2-6 (Garg ve ark., 1985), Bambynek ve arkadaşlarına göre \% 2-6 ve \% 3-7 (Bambynek ve ark., 1972) ve Broll'e göre \% 0.1-3 ve \% 0.3-5 (Broll, 1986) kadar farklılık vardır. Bu farklılıklar, Fink ve arkadaşlarının (Fink ve ark., 1966) sonuçları hariç, diğer araştırmacıların sonuçları ile uyum içindedir. 
Tablo 1. Deneysel ve Teorik K Tabakası Flüoresans Verim Değerleri

\begin{tabular}{|c|c|c|c|c|c|c|c|c|c|}
\hline \multirow[b]{2}{*}{ Sample } & \multirow[b]{2}{*}{$\begin{array}{c}\text { F Katkı } \\
\text { Miktarı } \\
(\%)\end{array}$} & \multirow[b]{2}{*}{$\begin{array}{c}\text { B Katkı } \\
\text { Miktarı } \\
(\%)\end{array}$} & \multicolumn{7}{|c|}{$\omega_{\mathrm{K}}$} \\
\hline & & & Mevcut Çalışma & $\begin{array}{c}\text { Krause, } \\
1979\end{array}$ & $\begin{array}{c}\text { Hubbell } \\
\text { ve ark., } \\
1994\end{array}$ & $\begin{array}{c}\text { Fink } \\
\text { ve ark., } \\
1966\end{array}$ & $\begin{array}{c}\text { Garg } \\
\text { ve ark., } \\
1985\end{array}$ & $\begin{array}{c}\text { Bambynek } \\
\text { ve ark., } \\
1972\end{array}$ & $\begin{array}{c}\text { Broll, } \\
1986\end{array}$ \\
\hline Katkısız ZnO & 0 & 0 & $0,4946 \pm 0,030$ & 0,4740 & 0,4810 & 0,440 & 0,482 & 0,479 & 0,490 \\
\hline F-katkılı $\mathrm{ZnO}$ & 1 & 0 & $0,5069 \pm 0,0380$ & & & & & & \\
\hline F-katkılı $\mathrm{ZnO}$ & 2 & 0 & $0,5032 \pm 0,0392$ & & & & & & \\
\hline F-katkılı $\mathrm{ZnO}$ & 3 & 0 & $0,4973 \pm 0,0338$ & & & & & & \\
\hline F-katkılı $\mathrm{ZnO}$ & 4 & 0 & $0,4905 \pm 0,0441$ & & & & & & \\
\hline F-katkılı $\mathrm{ZnO}$ & 5 & 0 & $0,4882 \pm 0,0435$ & & & & & & \\
\hline B-katkılı $\mathrm{ZnO}$ & 0 & 2 & $0,4915 \pm 0,0432$ & & & & & & \\
\hline B-katkılı $\mathrm{ZnO}$ & 0 & 3 & $0,5048 \pm 0,0454$ & & & & & & \\
\hline B-katkılı $\mathrm{ZnO}$ & 0 & 4 & $0,5086 \pm 0,0396$ & & & & & & \\
\hline B-katkılı $\mathrm{ZnO}$ & 0 & 5 & $0,5132 \pm 0,0384$ & & & & & & \\
\hline
\end{tabular}

Şekil 4’ten görüldüğü gibi, çinko oksit $(\mathrm{ZnO})$ ince filmlerine flor katkı miktarı arttıkça K tabakası flüoresans verim değerleri azalmaktadır. Bununla birlikte, Şekil 5'den görüldüğü gibi, ZnO ince filmlerine bor katkı miktarının artması ile K tabakası flüoresans verim değerleri de artmaktadır. Bunun nedeni flor katkılama miktarının artması ile K X-ışını yayınlama ihtimalinin azalması ve bor katkılama miktarının artması ile K X-1şını yayınlama ihtimalinin artması olabilir. Flor elektronegatifliği en büyük elementlerden olduğu için flor konsantrasyonu artması ile örgüdeki ara bölgelerin flor tarafından işgal edilme ihtimali de artar ve bu işgal kristaldeki örgü kusurlarının artmasına neden olur (Kerli, 2012; Kerli ve ark., 2014). Bununla birlikte, florun elektronegatifliğinin bordan daha büyük olması nedeniyle $\mathrm{F}^{-}$iyonun kristal yapıya girip ve $\mathrm{O}^{-2}$ iyonları ile yer değiştirme ihtimali bora göre daha fazladır. ZnO ince filmdeki çinkonun flor ve bor katkı miktarına göre $\mathrm{K}$ tabakası flüoresans verim değerlerindeki bu değişimlerin nedenlerinden biri de bu olabilir.

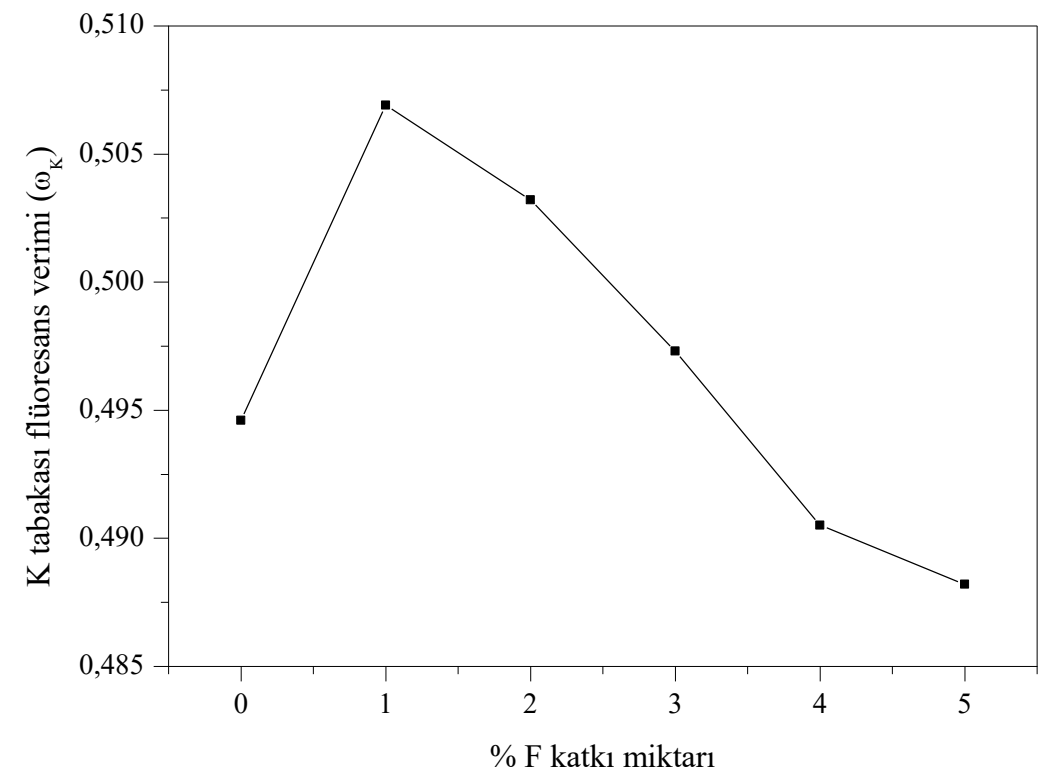

Şekil 4. Flor Katkı Miktarına Göre K Tabakası Flüoresans Veriminin Değişimi 


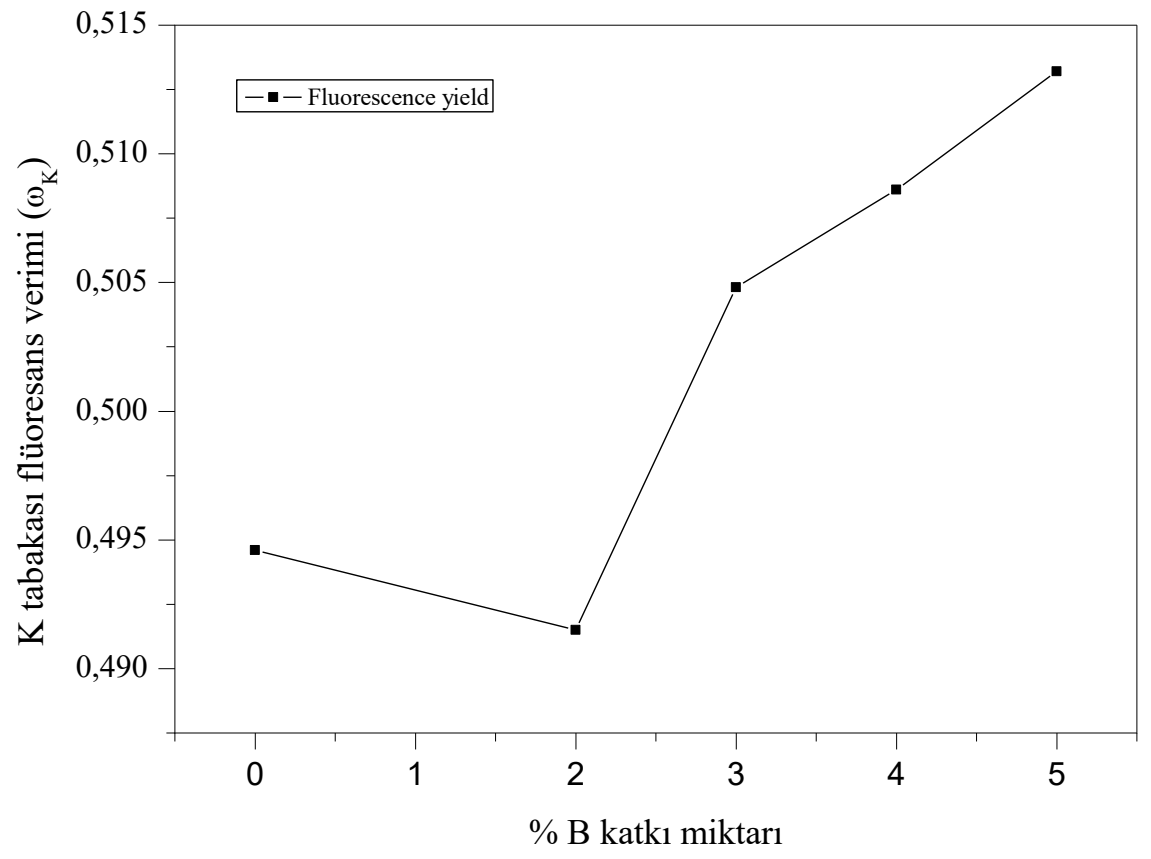

Şekil 5. Bor Katkı Miktarına Göre K Tabakası Flüoresans Veriminin Değişimi

K tabakası flüoresans verim değerinin flor ve bor katkı miktarlarına göre oluşan değişimlerinin nedenlerinden biri de, flor ve bor katkı miktarlarına bağlı olarak $\mathrm{ZnO}$ ince filmlerin yasak enerji aralıklarındaki artmalar ya da azalmalar olabilir. $\mathrm{Bu}$ artmalar ve azalmalar X-ı̧̧ını yayınlama ihtimalini arttırır ya da azaltabilir. Bunlara ek olarak, elementler kimyasal bileşiklerde yer alırlarsa, yayınladıkları X-ışını çizgisinin dalga boyunda, çizgi şiddetinde ve şeklinde değişimler görülebilir ve bu değişimler kimyasal etki olarak adlandırılır. K-kabuğu flüoresans verimine $\left(\omega_{\mathrm{K}}\right)$ kimyasal etkiler, birinci sıra geçiş elementlerinin kısmen doldurulmuş $3 \mathrm{~d}$ alt kabukları nedeniyle incelenen elementin kimyasal ortama bağlıdır. Bunlar; kimyasal bağ türü, kristal yapısı ve simetrisi, oksidasyon sayısı, değerliği, koordinasyon sayısı, elektronegatiflik, elektronların perdeleme etkisi, bağ uzunluğu gibi etkenlerdir. Moleküllerin, komplekslerin ve kristallerin yapısının karakteristik özellikleri, temel olarak K X-1şını yayınlama ihtimalini ve çizgi posizyonlarını etkiler. Aslında, bir molekül veya kristaldeki bir atom serbest atomdan farklıdır. Atomun kimyasal bir bağa katılması elektron yoğunluğunda değişikliğe neden olur ve değerlik elektron yoğunluğu yüksek bir dereceye kadar değiştirir. Elektron yoğunluğu, bir molekül veya kristal içindeki komşu atomlara bağlanma türüne bağlı olarak azalır veya artar. Değerlik elektronları moleküllerde bağlanmaya katıldıkları için, K X-ı̧̧ını yayınlama ihtimalleri ve geçişleri moleküllerin yapısına göre değişir. Kimyasal bağ oluşumuna katılan değerlik elektronları moleküllerin kimyasal yapılarını değiştirir ve bu etki hem elektron perdelemesinde ve hem de diş kabuk bağlama enerjilerinde değişikliğe neden olur. Böylece $\mathrm{K}$ kabuğu elektronlarının bağlanma enerjileri kimyasal ortamdan güçlü bir şekilde etkilenir ve K X-1şını yayınlama ihtimalini de değiştirir.

\section{SONUÇ VE ÖNERILER}

$\mathrm{Bu}$ araştırmada, katkısız ve belirli oranlarda flor ve bor katkılı $\mathrm{ZnO}$ ince filmlerinde çinkonun $\mathrm{K}$ kabuğu flüoresans veriminin değişimi ölçüldü. $\mathrm{ZnO}$ ince filmlerde çinkonun $\mathrm{K}$ kabuğu flüoresans verimlerinin \% 1-5 flor ve \% 2-5 bor katkı miktarlarına göre değiştiği tespit edildi. $\mathrm{ZnO}$ ince filmine flor katkı miktarı artarken çinkonu flüoresans verim değerlerinin azaldığı ve bor katkı miktarı artarken ise çinkonun flüoresans verim değerlerinin artığı gözlendi. \%1-5 flor ve \% 2-5 bor katkılı $\mathrm{ZnO}$ ince filmlerde çinkonun $\mathrm{K}$ kabuğu flüoresans verimlerinin flor ve bor katkı oranlarına göre değişmesinin nedeni, flor ve bor iyonlarının $\mathrm{ZnO}$ ince filminde oksijen iyonları ile yer değiştirmesi nedeniyle yüklerin yeniden yerleşimi veya yük transferi nedeniyle değerlik elektron konfigürasyonundaki değişim olabilir. Çünkü florun oksijenden daha büyük bir elektronegatiflik değeri vardır. Bu nedenle, oksijenden daha fazla değerlik elektronu çeker. Bor oksijenden ve çinkodan daha küçük bir elektronegatiflik değerine sahiptir ve dolayısıyla oksijenden daha az elektron çeker. Bu, çinkonun elektronik yapısının değişmesine neden olur ve bu da flor ve bor katkılı $\mathrm{ZnO}$ ince filmlerinde çinkonun $\mathrm{K}$ kabuğu flüoresans veriminde değişikliklerin olmasina neden olabilir.

Sonuç olarak, $\mathrm{ZnO}$ ince filmlerine flor ve bor katkı oranlarına göre flüoresans verim değerlerinin değişimlerinin nedenlerinin daha kesin olarak anlaşılabilmesi için $\mathrm{ZnO}$ ince filmlerine yüzde olarak daha çok sayıda, örneğin \%1-20 flor ve \%1-20 bor, flor ve bor katkılanarak ölçümlerin tekrar yapılması önerilmektedir. 


\section{KAYNAKLAR}

Bakoglidis K.D., Schmidt S., Garbrecht, M. Ivanov I.G., Jensen J., Greczynski G., Hultman L., (2015). Low-Temperature Growth of Low Friction Wear-Resistant Amorphous Carbon Nitride Thin Films by Mid-Frequency, High Power Impulse, and Direct Current Magnetron Sputering. J. Vac. Sci. Technol. A., 33(5): 05E112. DOI: 10.1116/1.4923275.

Bambynek W., Crasemann B., Fink R.W., Freund H.U., Mark H., Swift C.D., Price R.E., Rao P.V., (1972). X-Ray Fluorescence Yield, Auger and Coster-Kronig Transition Probabilities, Rev. Mod. Phys., 44(4), 716-813.

Baydaş E., Oz Orhan E., Büyükyıldız M., (2009). Measurements of K-shell Fluorescence Yields for Ti, V, Cr, Fe, Co, Ni and Cu Elements and Their Halogen Compounds, Turk Journal of Phys, 33, 311-316.

Broll N., (1986). Quantitative X-ray Fluorescence Analysis. Theory and Practice of Fundamental Coefficients Method, X-ray Spectrometry, 15, 271-285.

Chen W., Zhu L., Li Y., Hu L., Guo Y., Xu H., Ye Z., (2013). Origin of Highly Stable Conductivity of H Plasma Exposed ZnO Films, Phys. Chem. Chem. Phys., 15 (41), 17763-17766.

Cho S.H., Cho C. K., Hwang W.J., Eun K.T., Kim H K., (2011). Mechanical Integrity of Flexible InZnO/Ag/InZnO Multilayer Electrodes Grown by Continuous Roll-to-Roll Sputtering, Solar Energy Materials and Solar Cells, 95(12), 3442-3449.

Dhara S., Giri P.K., (2012). Stable p-type Conductivity and Enhanced Photoconductivity from Nitrogen-Doped Annealed ZnO Thin Film, Thin Solid Films, 520(15), 5000-5006.

Fahrenbruch, A.L., (1997), II-VI Compounds in Solar Energy Conversion, Journal of Crystal Growth, 39, 73-91.

Fink R.W., Jopson R.C., Mark H. and Swift D.C., (1966). Atomic Fluorescence Yields, Rev. Mod. Phys., 38, 513-540.

Gallop J., Hao L., (2016). Nanoscale Superconducting Quantum Interference Devices Add Another Dimension. ACS Nano., 10(9), 8128-8132. DOI: 10.1021/acsnano.6b04844.

Garg M.L., Mehta D., Kumar S., Mangal P.C. and Trehan P. N., (1985). Energy Dependence of Photon- Induced: Ka and K, XRay Fluorescence Cross Sections for some Elements with $20<Z<56, X$-Ray Spectrom.14, 165-169.

Hubbell J.H., Seltzer S.M., (1995). Tables of X-Ray Mass Attenuation Coefficients and Mass Energy-Absorption Coefficients 1 $\mathrm{keV}$ to $20 \mathrm{MeV}$ for Elements $\mathrm{Z}=1$ to 92 and 48 Additional Substances of Dosimetric Interest, NISTIR 5632, U.S. Department of Commerce Technology Administration National Institute of Standards and Technology Physics Laboratory Ionizing Radiation Division Gaithersburg, MD 20899.

Hubbell J.H., Trehan, P.N., Singh N., Chand B., Mehta D., Garg M. L., Garg R.R., Singh S., Puri S., (1994). A Review, Bibliography, and Tabulation of K, L, and Higher Atomic Shell X-Ray Fluorescence Yields, J. Phys. Chem. Ref. Data 23, 339364.

Ip K., Overberg M.E., Heo Y.W., Norton D.P., Pearton S.J., Stutz C.E., Luo B., Ren F., Look D.C., Zavada J.M., (2003). Hydrogen Incorporation and Diffusivity in Plasma Exposed Bulk ZnO, Appl. Phys. Lett., 82(3), 385-387.

Kahoul A., Abassi A., Deghfel B., Nekka M., (2011). K-shell Fluorescence Yields for Elements with $6 \leq \mathrm{Z} \leq 99$, Radiation Physics and Chemistry 80, 369-377.

Krause M.0., (1979). Atomic Radiative and Radiationless Yields for K and L Shells, J. Phys. and Chern. Ref. Data, 8, 307-327.

Kerli S., (2012). Bor-Flor Katkılı Zno İnce Film ve Parçacıkların Üretimi, Fiziksel Özelliklerinin İncelenmesi, Doktora Tezi, KSÜ Fen Bilimleri Enstitüsü, Fizik Anabilim Dalı, p.128.

Kerli S., Alvera U., Yaykaslı H., Tekerek S., (2014). Flor Katkılı ZnO İnce Filmlerin Üretimi ve Fiziksel Özelliklerinin İncelenmesi, Düzce Üniversitesi Bilim ve Teknoloji Dergisi 2, 56-63.

Li Q., Zhu L., Li Y., Zhang X., Niu W., Guo Y., Ye Z., (2017). Highly Conductive Thin Films of Nonmetal F and B Co-doped $\mathrm{ZnO}$ on Flexible Substrates: Experiment and First-Principles Calculations, Journal of Alloys and Compounds, 697,156-160.

Naik G.V., Shalaev V.M., Boltasseva A., (2013). Alternative Plasmonic Materials: Beyond Gold and Silver, Adv. Mater., 25 (24), 3264-3294.

Natsume Y., Sakata H., (2000). Zinc Oxide Films Prepared by Sol-Gel Spin Coating, Thin Solid Films, 372, 30-36. 
Nian Q., Zhang M.Y., Schwartz B.D., Cheng G.J., (2014). Ultraviolet Laser Crystallized ZnO:Al Films on Sapphire with High Hall Mobility for Simultaneous Enhancement of Conductivity and Transparency, Appl. Phys. Lett., 104, [201907].

Nomura K., Ohta H., Ueda K., Kamiya T., Hirano M., Hosono H., (2003). Thin-Film Transistor Fabricated in Single-Crystalline Transparent Oxide Semiconductor, Science, 300(5623), 1269-1272.

Pious J.K., Balakrishna K. M., Lingappa N. and Siddappa K., (1992). Total K Fluorescence Yields for Fe, Cu, Zn, Ge and Mo, J. Phys. B., 25, 1155-1160.

Salam S., Islam M., Akram A., (2013). Sol-gel Synthesis of Intrinsic and Aluminium-Doped Zinc Oxide Thin Films as Transparent Conducting Oxides for Thin Film Solar Cells, Thin Solid Films, 529, 242-247.

Söğüt Ö., Dönük Ç., Apaydın G., Bakkaloğlu Ö.F., (2014). Examination of CoNiCu Thin Films by Using XRF and XRD, Can. J. Phys., 92, 435-439. doi.org/10.113/cjp-2012-0538.

Şimşek Ö., Yılmaz S., Karagöz D., Ertuğrul M., (2002). Measurement of K shell Fluorescence Cross Sections and K Shell Fluorescence Yields for the Atomic Region $22 \leq Z \leq 64$ by $59.5 \mathrm{keV}$ Photons, Journal of Radioanalytical and Nuclear Chemistry, 253(1), 143-147.

Tıraşoğlu E., Söğüt Ö., (2008). Determination of Experimental K-Shell Fluorescence Yield for Potassium and Calcium Compounds, Pramana Journal of Physics, 70(3), 471-477.

Tsay C., Fan K., Chen S., Tsai C., (2010). Preparation and Characterization of ZnO Transparent Semiconductor Thin Films by Sol-Gel Method, Journal of Alloys and Compounds, 495, 126-130.

Wang T., Radovanovic P.V., (2010). Free Electron Concentration in Colloidal Indium Tin Oxide Nanocrystals Determined by Their Size and Structure, J. Phys. Chem. C., 115(2), 406-413.

Wong L.M., Chiam S.Y., Huang J.Q., Wang S.J., Pan J.S., Chim W.K., (2011). Role of Oxygen for Highly Conducting and Transparent Gallium-Doped Zinc Oxide Electrode Deposited at Room Temperature, Appl. Phys. Lett., 98(2), [022106].

Zhang S., (2010). Nanostructured Thin Films and Coatings: Mechanical Properties, CRC Press, Boca Raton, Florida, USA, 550s, ISBN: 9781420094022.

Zou X., Liu X., Wang C., Jiang Y., Wang Y., Xiao X.H., (2012).Controllable Electrical Properties of Metal-Doped In2O3 Nanowires for High-Performance Enhancement Mode Transistors, ACS Nano, 7 (1), 804-810. 